\title{
Manejo Sanitário do rebanho leiteiro e resíduos de inseticidas Piretróides em leite de vaca produzido no município de Chapada dos Guimarães, Brasil*
}

\author{
Sanitary Management of milk producing cows and insecticide Pyrethroids residue \\ in cow milk produced on Chapada dos Guimarães, Brazil
}

\author{
Thais Hernandes ${ }^{1}$, Milena Athie Goulart' ${ }^{2}$ Eliana Freire Gaspar de Carvalho Dores ${ }^{1}$, \\ Márcia Prado 3 \& Olaf Malm ${ }^{4}$
}

\begin{abstract}
RESUMO
A atividade leiteira no Brasil enfrenta sérias dificuldades para atingir produtividade e lucratividade, a endemia de ectoparasitas e o manejo sanitário deficiente são fatores que colaboram para o quadro atual. Mediante esses fatos, propõe-se o presente trabalho, com objetivo de caracterizar propriedades produtoras de leite de Chapada dos Guimarães, Brasil, quanto ao manejo sanitário e analisar inseticidas piretróides em leite. Com auxílio de um questionário, entrevistas e observação in loco, foram avaliadas 40 propriedades. Foram analisadas 69 amostras de leite in natura, o método de análise dos piretróides em leite foi baseado na dispersão da matriz em fase sólida com Celite ${ }^{\circledR}$, utilizando CG/DCE. As propriedades possuem extensões entre 4 e 600 hectares (80\%). A mosca do chifre (Haematobia irritans) foi apontada como sendo de forte infestação por 58\% dos produtores, seguida pelo carrapato Boophilus microplus (42\%). O controle da infestação parasitária por inseticidas é a prática de $92 \%$ dos produtores da região, sendo que $71 \%$ dos produtos utilizados tinham princípio ativo da classe dos piretróides, cipermetrina e deltametrina. Em 14 amostras (21\%), foram detectados resíduos de cipermetrina entre traços e $0,012 \mu \mathrm{g} \mathrm{g}^{-1} \mathrm{e} \mathrm{em}$ 3 amostras foram detectados resíduos de deltametrina em concentrações de $0,012 \mu \mathrm{g} \mathrm{g}^{-1}$. Estes resultados indicaram que as práticas pecuárias da região de estudo têm como consequência a presença de resíduos no leite produzido. Os resultados demonstraram que o uso de inseticida necessita ser racionalizado e os resíduos devem ser monitorados para garantir a qualidade do alimento produzido, os produtores devem ser orientados sobre as boas práticas agrícolas, de modo a levar a um uso racional dessas substâncias.
\end{abstract}

Descritores: manejo sanitário, leite, piretróides, resíduos.

\section{ABSTRACT}

The milk production activity in Brazil has been facing several difficulties to achieve good productivity and profitability. The endemics of ectoparasites and the deficient sanitary management are factors collaborating to the present situation. Considering that, proposed to the present study aimed to characterize the milk production activity in Chapada dos Guimarães, Brazil, regarding the sanitary management and the analysis of pyrethroids in milk. Using a questionnaire, interviews and observation in situ were evaluated 40 properties. We analyzed 69 samples of milk in natura, the method for the determination of deltamethrin and cypermethrin in bovine milk is based on matrix solid-phase dispersion (MSPD) with Celite $囚$, followed by GC-ECD analysis. The properties have extensions from 4 to 600 hectares (80\%). The horn of the fly (Haematobia irritans) was identified as being of strong infestation by $58 \%$ of producers, followed by the tick Boophilus microplus (42\%). The control of parasitic infestation by insecticides is the practice of $92 \%$ of producers in the region, with $71 \%$ of the products used had active principle of the class of pyrethroids, cypermethrin and deltamethrin. Residues of cypermethrin were detected in 14 samples (21\%) in concentrations up to $0,012 \mu \mathrm{g} \mathrm{g}^{-1}$ and deltamethrin was detected in 3 samples at $0,012 \mu \mathrm{g} \mathrm{g}^{-1}$. These results indicate that the practices used in the study region have as consequences the presence of pyrethroids residues in the produced milk. In order to guarantee the quality of this important food, the produced milk should be monitored and the producers should be oriented to use good agricultural practices aiming to improve the sanitary management of the milk producing cows.

Keywords: sanitary management, milk, pyrethroids, residues.

*Trabalho originado da Tese de Doutorado do primeiro autor. Programa de Pós-graduação em Ciências de Alimentos, Universidade Federal do Rio de Janeiro (PPGCA - UFRJ). 'Universidade Federal de Mato Grosso (UFMT), Av. Fernando Corrêa, s/n, Coxipó, $78080-900$ Cuiabá, MT, Brasil. ${ }^{2}$ Escola Técnica Federal de Mato Grosso. ${ }^{3}$ Secretaria de Saúde do Estado de Mato Grosso. ${ }^{4}$ UFRJ/Instituo de Biofísica. CORRESPONDÊNCIA: T. Hernandes [thaisher@gmail.com ; Fax +55 (65) 3615 8764]. 


\section{INTRODUÇÃO}

A ocorrência de infestações de parasitas como o carrapato (Boophilus microplus) assume papel de fundamental importância na produtividade agropecuária [10]. O carrapato, por ser um parasita hematófago, causa a espoliação constante, provocando irritação no animal, interferindo na alimentação e, por consequência, diminuição da produção de leite. Esse parasita serve de agente transmissor do complexo da "tristeza parasitária" e como facilitador da entrada de bactérias e larvas (berne e miíase) [21]. Foram estimadas perdas de dois bilhões de dólares anuais por causa da infestação de carrapatos, parte desse prejuízo (40\%), sendo atribuído ao controle químico para o combate aos ectoparasitas e à diminuição na produtividade [13,21]. Ainda, em muitos países, o manejo sanitário por meio de inseticidas é o mais utilizado, todavia, essa prática mostra-se pouco eficiente, principalmente quando mal empregada, pois estimula a resistência aos princípios ativos, além de poder deixar resíduos no leite $[3,4,11,12,16]$. O Brasil apresenta grande extensão de pasto, o maior rebanho leiteiro comercial do mundo e uma produtividade abaixo das de muitos países [12]. Os contrastes seguem também entre as regiões geográficas, tanto na produção quanto no manejo sanitário do rebanho. Mediante esses fatos, o objetivo do presente trabalho é investigar as características, a produção e a forma de manejo sanitário de propriedades produtoras de leite no município de Chapada dos Guimarães, Brasil, e analisar resíduos de inseticidas no leite produzido nessa localidade.

\section{MATERIAIS E MÉTODOS}

O trabalho foi desenvolvido de janeiro de 2004 a janeiro de 2005 e foi executado em duas etapas: a primeira, levantamento dos dados, para caracterização da amostra. Fizeram parte do estudo 40 propriedades produtoras de leite no município de Chapada dos Guimarães. Para essa etapa foi empregado um questionário semiestruturado na caracterização da propriedade quanto à extensão, tamanho do rebanho leiteiro, produção, infestação do gado; tipo dos produtos veterinários, uso e frequência de aplicação dos inseticidas; entendimento dos trabalhadores quanto ao risco do manuseio e a formas de prevenção de acidentes no uso de inseticidas.

$\mathrm{Na}$ segunda etapa, foram selecionadas 12 propriedades para coleta e análise do leite, considerando as características diferenciadas de uso dos inseticidas e tamanhos das propriedades. As coletas foram realizadas mensalmente, no período de agosto de 2004 a janeiro de 2005, na primeira hora do dia, antes que o leite fosse enviado ao laticínio ou depositado no resfriador, contabilizando seis coletas, cobrindo meses de seca (agosto, setembro e início de outubro) e de chuva (final de outubro a janeiro). O leite foi coletado diretamente do latão, com uso de conchas de aço inoxidável, depositado em garrafas de vidro cor âmbar, esterilizadas e previamente identificadas. As amostras foram imediatamente acondicionadas numa caixa com gelo e conduzidas ao Laboratório de Análise de Resíduos de Biocidas - LARB/UFMT, onde foram mantidas em freezer e analisadas em, no máximo, 48 horas. As amostras foram analisadas a partir da metodologia desenvolvida e validada [14], que apresentou limite de detecção de $0,009 \mu \mathrm{g} \mathrm{g}^{-1}$ para a deltametrina e $0,010 \mu \mathrm{g} \mathrm{g}^{-1}$ para a cipermetrina.

A metodologia constou dos seguintes passos: foram pesados $5 \mathrm{~g}$ de leite in natura, aos quais foram adicionados $5 \mathrm{~mL}$ de acetona, que foram agitados por 5 minutos em agitador mecânico horizontal a $90 \mathrm{rpm}$. A 2,0 g de Celite $\AA$ (previamente condicionada a $150^{\circ} \mathrm{C}$, por 8 horas) foram adicionados $10 \mathrm{~mL}$ de uma solução extratora acetona-n-hexano (3:7) e a suspensão ao leite previamente preparada. Esta mistura foi extraída 4 vezes, com $10 \mathrm{~mL}$ da solução extratora, agitando por 20 minutos, em agitador mecânico horizontal, a 90 rpm. $\mathrm{O}$ extrato foi concentrado em atmosfera de nitrogênio e retomado a $1 \mathrm{~mL}$ em tolueno. Ao extrato final, foi adicionado 22,5 ng do padrão interno de aldrin, que foi analisado em cromatógrafo a gás com detecção por captura de elétrons. Os resultados positivos foram confirmados em cromatográfo a gás com detector de espectrometria de massas.

\section{RESULTADOS}

Constatou-se que as propriedades produtoras de leite pesquisadas possuíam extensões variadas, de áreas pequenas de 4 a 100 hectares $(47,5 \%)$, a propriedades formadas com extensões entre 101 e 600 ha $(35,5 \%)$ e uma menor proporção entre 601 e 2000 ha (20\%). A região apresentou uma relação de 31,1 vacas ordenhadas por estabelecimento produtor e atingiu uma média anual de cerca de 20 mil litros de leite por unidade produtiva. O leite na região possuía preço que variava entre $R \$ 0,21$ e 0,50 por litro. 
O carrapato foi apontado como sendo de forte infestação por $42 \%$ dos produtores. A época do ano considerada crítica para a infestação desse inseto foi a seca, para $34 \%$ dos produtores, sendo que para os produtores que estão localizados em regiões de vales (21\%), a infestação não diminui durante todo o ano. A mosca do chifre, Haematobia irritans, foi apontada por $58 \%$ dos produtores como tendo uma forte infestação, e apenas $3 \%$ declararam não ter essa infestação. A época do ano apontada como de maior incidência, por $66 \%$ dos entrevistados, foi a chuvosa.
Constatou-se que a maior parte dos produtores da região utilizava inseticidas para controle da infestação dos parasitas (92\%). Na Tabela 1, estão elencados os produtos utilizados para controle dos insetos.

Os produtos mais utilizados foram Barrage e Butox (deltametrina). Observou-se que a maioria dos produtos utilizados tinha princípio ativo da classe dos piretróides, cipermetrina e deltametrina, perfazendo um total de $71 \%$ dos produtos usados. Outras substâncias eram utilizadas em menor percentual, sendo $10 \%$ de organofosforados; $4 \%$ de carbamatos e $15 \%$ de outras

Tabela 1. Relação do número e porcentual dos usuários e dos inseticidas com respectivos princípios ativos utilizados nas 40 propriedades rurais do entorno do município de Chapada dos Guimarães, MT, Brasil, no levantamento realizado entre janeiro e julho de 2004.

\begin{tabular}{|c|c|c|c|c|}
\hline Produtos & $\begin{array}{c}\text { N. de } \\
\text { usuários }\end{array}$ & $\begin{array}{c}\text { \% do total de } \\
\text { usuários }\end{array}$ & Princípios ativos & Classe química \\
\hline Barrage & 13 & 32 & cipermetrina & piretróide \\
\hline Butox & 18 & 45 & deltametrina & piretróide \\
\hline Ciperpurina & 3 & 7 & cipermetrina & piretróide \\
\hline Cypermetril & 3 & 7 & cipermetrina & piretróide \\
\hline Cipex & 1 & 2 & cipermetrina & piretróide \\
\hline Cypermil & 1 & 2 & cipermetrina & piretróide \\
\hline Cipertroide & 2 & 5 & cipermetrina & piretróide \\
\hline Ec-tox ce $15 \%$ & 1 & 2 & cipermetrina & piretróide \\
\hline Ectogard & 1 & 2 & cipermetrina & piretróide \\
\hline Ectobon & 1 & 2 & permetrina & piretróide \\
\hline Ectoplus & 1 & 2 & cipermetrina & piretróide \\
\hline K-otrine & 1 & 2 & deltametrina & piretróide \\
\hline Flytick & 2 & 7 & cipermetrina & piretróide \\
\hline Ivomec & 4 & 10 & ivermectina & Lactonas macrocíclicas \\
\hline Triatox & 4 & 10 & amitraz & triazopentadieno \\
\hline Bolfo & 1 & 2 & propoxur & carbamato \\
\hline Tira berne & 2 & 5 & diclorvox & organofosforado \\
\hline Tanidil & 2 & 5 & $\begin{array}{l}\text { propoxur e } \\
\text { coumaphós }\end{array}$ & $\begin{array}{c}\text { carbamato e } \\
\text { organofosforado }\end{array}$ \\
\hline Flution & 1 & 2 & tiguvon & organofosforado \\
\hline Neguvon & 2 & 5 & triclorfon & organofosforado \\
\hline Duotin & 1 & 2 & abamectina & avermectina \\
\hline Amitraz & 1 & 2 & amitraz & triazopentadieno \\
\hline não usa & 3 & 7 & - & - \\
\hline
\end{tabular}


substâncias como a ivermectina. A aplicação desses produtos era realizada nas propriedades menores pelos proprietários e nas maiores por empregados, com periodicidades variáveis. As aplicações podiam ocorrer a cada quinze ou vinte dias e estimou-se que esse controle ocorria de 18 a 24 vezes ao ano.

No presente estudo, $42 \%$ dos entrevistados não utilizavam proteção individual para o manuseio dessas substâncias. Dentre aqueles que fazem uso, $34 \%$ usam somente proteção como pano no rosto e aplicação a favor do vento, não utilizando efetivamente equipamentos de segurança.

A recomendação de carência não foi obedecida na região estudada, pois a maioria $(63 \%)$ dos entrevistados afirmou aplicar o produto à tarde e ordenhar na manhã do dia seguinte.

Dentre 69 amostras de leite analisadas, em 14 , foram detectados resíduos de cipermetrina entre traços e $0,012 \mu \mathrm{g} \mathrm{g}^{-1}$ e dentre essas foram detectados resíduos de deltametrina em 3 amostras com concentrações de $0,012 \mu \mathrm{g} \mathrm{g}^{-1}$. As amostras com resíduos representaram $21 \%$ do leite analisado na região.

\section{DISCUSSÃO}

Embora o Brasil encontre-se numa posição privilegiada em quantidade de cabeças de gado leiteiro, a sua produtividade ocupava o sexto lugar ranking mundial no ano de 2006 [12,15]. No cenário nacional, destaca-se a região Sudeste com 38,4\% da produção nacional, seguida pela Região Sul, com $27,7 \%$. Minas Gerais é o principal estado produtor, respondendo, isoladamente, por $27,9 \%$ do total. $\mathrm{Na}$ região Centro-Oeste, o estado que destaca-se é Goiás, com $70 \%$ da produção de leite regional, seguida pelo estado de Mato Grosso, esse, por sua vez, possui vasta pastagem, grande rebanho para corte e uma produção de leite muito inferior aos estados citados [15]. Alguns fatores foram apontados pelos produtores pesquisados que justificam essa realidade, a produção de gado de corte requer um custo menor com mão de obra e possui maior rentabilidade. O leite, na região, possui um preço muito baixo e, como em outros estados do Brasil, esse preço não cobre os custos de produção, o qual pode variar, em Minas Gerais, de $\mathrm{R} \$ 0,54$ a $0,71[9,19,21]$.

Os produtores apontaram alta incidência de carrapato nos meses de maio a outubro e mosca do chifre nos meses de novembro a março, todavia o ataque desses parasitas persiste durante todo o ano, com menor intensidade. Essa região estudada é formada por planície e vales, sendo que no primeiro a umidade relativa do ar é menor do que no segundo, propiciando, nos vales, uma maior infestação desses ectoparasitas. O carrapato bovino, Boophilus microplus, é adaptado às variações climáticas e resistentes a diversas formulações veterinárias [24]. A variabilidade de raças, a mestiçagem e as variações climáticas favorecem seu ciclo reprodutivo, fatores que contribuem para a endemicidade do ectoparasita em várias regiões do Brasil, como observado na região estudada [6]. A mosca do chifre foi outro inseto destacado pelos produtores, detectada no Brasil a partir da década de 70, que também contribui para redução de peso do gado e diminuição da produção de leite [8].

$\mathrm{O}$ alto porcentual de uso de inseticidas foi semelhante ao encontrado no estado do Paraná [12]. Os produtores que não utilizavam os inseticidas eram os proprietários de pequenas propriedades com um número pequeno de cabeças de vacas. Foi relatada pelos entrevistados a resistência tanto do carrapato quanto da mosca do chifre, o que força a prática de revezamento de produtos.

$\mathrm{O}$ uso da classe de inseticidas piretróides é bastante difundido na Região Centro-Oeste. No norte do Mato Grosso, foi verificada uma frequência de uso de $79 \%$, e, no Mato Grosso do Sul, o uso foi de 69\% [5,20]. Essa frequiência de uso é muito maior quando comparada com resultados obtidos no estado do Paraná, de 22,5\% de piretróides [12]. Outro fator muito acima do mencionado pelo estudo realizado no Paraná foi a recorrência de uso de inseticidas na região de estudo. Essa é em média 3 vezes maior quando comparado o relatado por produtores de leite do Paraná [12].

Evidencia-se que o uso intensivo dos inseticidas é ineficiente no controle da infestação desses parasitas. O controle químico é questionado em muitos países. Foram relatadas inúmeras tentativas frustradas para combater o carrapato utilizando o controle químico, desde a introdução do carrapato na Austrália, em 1870, e Frisch (1999) verificou, em seu trabalho, que o aumento da resistência do bovino, em combinação com vacinas contra o carrapato, poderia eliminar uso rotineiro de acaricidas [11]. $\mathrm{Na}$ África, as limitações associadas aos atuais métodos de controle de doenças causadas pelo carrapato conduzem à necessidade de reduzir a dependência do uso 
intensivo acaricidas, indicando assim, a importância da pesquisa de novas estratégias de controle, mais seguras, mais baratas, mais eficazes e sustentáveis [16].

Muitas são as desvantagens do uso do controle químico, principalmente por que esse requer conhecimentos técnicos, os quais não fazem parte da realidade dos trabalhadores rurais [18]. Além de comprovadamente ineficaz para o controle dos ectoparasitas essas substâncias tóxicas representam risco à saúde do trabalhador rural que se expõem aos inseticidas sem a devida proteção. Outra desvantagem no uso de inseticidas no manejo sanitário são os resíduos no leite, foi verificada a falta de boas práticas agropecuárias até mesmo em regiões de alta produtividade como Minas Gerais [4]. As recomendações de carência para a ordenha são muito variadas, algumas bulas dos produtos indicam não haver resíduos da substância no leite, outros recomendam de 24 horas até 5 dias, enquanto para produtos contendo cipermetrina e alfacipermetrina, $o$ tempo de carência é de até 14 dias, como no caso do produto Butox ${ }^{\circledR}$ [8]. O maior intervalo mencionado pelos produtores, decorrido da aplicação até a ordenha foi de 72 horas, devido ao revezamento na aplicação nos animais.

Os produtores, em cujas amostras de leite foi detectado resíduos de piretróides, informaram ter utilizado inseticidas até um mês antes da data da coleta do leite. Em um estudo experimental, foram detectados resíduos de piretróides no leite até 35 dias após a aplicação do produto veterinário [3]. Em humanos, a excreção de metabólitos persiste por 7 a 10 dias, sugerindo a possível estocagem na derme e a baixa circulação sistêmica. É observado pico de excreção urinária de metabólitos entre 14 e 36 horas [2].

Essas substâncias são consideradas pouco tóxicas para mamíferos, porém, cada dia, seus resíduos estão mais presentes nos alimentos, não se podendo desconsiderar que a contaminação de alimentos é a forma mais importante de exposição a agrotóxicos [23].
Embora as concentrações encontradas estejam abaixo do estabelecido pelo Codex Alimentarius $\left(0,02 \mu \mathrm{g} \mathrm{g}^{-1}\right.$ para cipermetrina e $0,05 \mu \mathrm{g} \mathrm{g}^{-1}$ para deltametrina), não foram encontrados, na bibliografia nacional e estrangeira, trabalhos que monitorassem a contaminação de leite por piretróides, impossibilitando a comparação desses resultados com trabalhos semelhantes.

Os resíduos de piretróides no leite podem não ser representativos, levando-se em conta sua possibilidade de degradação nos processos de conservação do alimento. Todavia, o leite é apenas uma das matrizes alimentares que podem contribuir para a ingesta de piretróides, sendo que diversos estudos têm detectado resíduos desses inseticidas em diferentes vegetais $[1,7,17]$.

Verificou-se que as práticas pecuárias na região têm como consequência a presença de resíduos de piretróides no leite produzido. Esses devem ser monitorados, para garantir a qualidade do alimento produzido e para prevenção. Os produtores devem ser orientados para as boas práticas agrícolas, de modo a levar a um uso racional dessas substâncias.

\section{CONCLUSÃO}

A falta de conhecimento dos produtores quanto ao risco no manuseio dessas substâncias perigosas é um risco à saúde desses trabalhadores. O manejo sanitário na região estudada é realizado exclusivamente por inseticida, em sua grande maioria da classe dos piretróides. A possível não observância da carência do produto e o seu uso intensivo pode ter sido a causa da detecção dos resíduos nas amostras.

Embora os níveis encontrados tenham sido abaixo do permitido, alerta-se para o indício de contaminação desse alimento tão importante para a nutrição, inclusive de lactentes, expondo organismos ainda imaturos a substâncias perigosas.

Agradecimentos. À FAPEMAT, pelo financiamento do projeto.

\section{REFERÊNCIAS}

1 Agência Nacional de Vigilância Sanitária. 2007. Relatório de Atividades 2001 - 2006. 2:1-19. [Fonte:<http:// www.anvisa.gov.br/toxicologia/residuos/rel_anual_2001-2006.pdf].

2 Agency for Toxic Substances and Disease Registry. 2003. Toxicological Profile for Pyrethrins and Pyrethroids. 141: 1-281 [Fonte: <http://www.atsdr.cdc.gov/toxpro2.html].

3 Bissacot D.Z. \& Vassilieff I. 1997. Pyrethroid Residue in milk and Blood of Dairy Cows Following Single Topical Applications. Veterinary \& Human Toxicology. 39: 6-8. 
4 Brito J.R.F., Pinto S.M., Souza G.N.,Arcuri E.F., Brito M.A.V.P. \& Silva M.R. 2004. Adoção de boas práticas agropecuárias em propriedades leiteiras da Região Sudeste do Brasil como um passo para a produção. Acta Scientiae Veterinariae. 32: 125-131.

5 Caíres S.M. \& Castro J.G.D. 2002. Levantamento dos agrotóxicos usados por produtores rurais do município de Alta Floresta - Mato Grosso. Revista de Biologia e Ciências da Terra. 2: 1-17.

6 Campos Júnior D.A. \& Oliveira P.R. 2005. Avaliação in vitro da eficácia de acaricidas sobre Boophilus microplus (Canestrini, 1887) (Acari: Ixodidae) de bovinos no município de Ilhéus, Bahia, Brasil. Ciência Rural. 35: 1386-1392.

7 Columé A., Cardenas S., Gallego M., Valcarcel M. 2001. Selective enrichment of 17 pyrethroids from lyophilised agricultural samples. Journal of Chromatography A. 912: 83-90.

8 CPVS - Compêndio de Produtos Veterinárias. 2007. [Fonte: <http://www.cpvs.com.br/cpvs/index.html>].

9 Fassio L.H., Pereira Reis R., \& Geraldo L.G. 2006. Desempenho técnico e econômico da atividade Leiteira em Minas Gerais. Ciência e Agrotecnologia.. 30: 1154-1161.

10 Fragas A.B., Alencar M.M., Figueiredo L.A., Razook A.G. \& Cyrillo J.N.S.G. 2003. Análise de Fatores Genéticos e Ambientais que Afetam a Infestação de Fêmeas Bovinas da Raça Caracu por Carrapatos (Boophilus microplus). Revista Brasileira de Zootecnia. 32:1578-1586.

11 Frisch J.E. 1999. Towards a permanent solution for controlling cattle ticks. International Journal for Parasitology. 29 : $57-$ 71.

12 Godoy F., Hastenpflug M., Balbé T.A.F., Estivalet Junior C.N.O. \& Gouvêa A. 2006. Manejo Sanitário do Rebanho Leiteiro na Região Sudoeste do Paraná. Synergismus scyentifica UTFPR. 1: 167-172.

13 Grisi L., Massard C.L., Borja G.E.M. \& Pereira J.B. 2002. Impacto econômico das principais ectoparasitoses em bovinos no Brasil. A Hora Veterinária. 21: 8-10.

14 Hernandes T. 2007. Análise de Micropoluentes Orgânicos em Alimentos Lácteos no Estado de Mato Grosso - MT. $94 f$. Rio de Janeiro, RJ. Tese de Doutorado em Ciências - Programa de Pós-Graduação em Ciências de Alimentos, Universidade Federal do Rio de Janeiro.

15 Instituto Brasileiro de Geografia e Estatística (IBGE). 2007. Produção da Pecuária Municipal 2006. [Fonte:<http:// www.ibge.gov.br/home/presidencia/noticias/noticia_impressao.php?id_noticia=1053].

16 Kivaria F.M. 2007. The control of East Coast Fever in Africa: A constant battle for impoverished dairy farmers. The Veterinary Journal. 174: 221-222.

17 Oviedo M.T.P., Toledo M.C.F. \& Vicente E. 2003. Resíduos de agrotóxicos piretróides em hortaliças. Pesticidas: Pesticidas: Revista de Ecotoxicologia e Meio Ambiente. 13: 9 -18.

18 Peres F. \& Moreira J.C. 2003. É veneno ou é remédio? Agrotóxicos, saúde e ambiente. Rio de Janeiro: Editora Fiocruz, $384 \mathrm{p}$.

19 Prado E., Geraldo L.G. \& Cardoso B.M. 2007. Rentabilidade da exploração leiteira em uma propriedade durante cinco anos. Arquivo Brasileiro de Medicina Veterinária e Zootecnia. 59: 501-507.

20 Rodrigues S.R., Sanches C.S., Fialho E.M.L.M., Ismael A.P.K. \& Barros A.T.M. 2002. Comercialização e uso de produtos inseticidas para controle da mosca-dos-chifres em Aquidauana, MS. Embrapa Pantanal. Boletim de Pesquisa e Desenvolvimento, 32, 23p.

21 Rocha C.M.B.M., Oliveira P.R., Leite R.C., Cardoso D.L., Calic S.B. \& Furlong J. 2006. Percepção dos produtores de leite do município de Passos, MG, sobre o carrapato Boophilus microplus (Acari: Ixodidae), 2001. Ciência Rural. 36: 1235-1242.

22 Schettgen T., Heudorf U., Drexler H. \& Angerer J. 2002. Pyrethroid exposure of the general population-is this due to diet. Toxicology Letters. 134: 141-145.

23 Souza A.P., Sartor A.A. \& Bellatov P.S. 2003. Eficácia de Carrapaticidas em Rebanhos de Bovinos Leiteiros de Municípios da Região Centro-Sul do Paraná. Revista de Ciências Agroveterinárias. 2: 131-135.

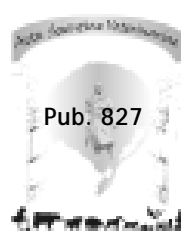

